\title{
Eficiência da utilização dos recursos renováveis nas universidades federais
}

\author{
Maria Aparecida Curi \\ Universidade Federal de Alfenas (UNIFAL/MG) \\ Gideon Carvalho de Benedicto \\ Universidade Federal de Lavras (UFLA) \\ Francisval de Melo Carvalho \\ Universidade Federal de Lavras (UFLA) \\ Adriano Antonio Nuintin \\ Universidade Federal de Alfenas (UNIFAL/MG) \\ Leandro Rivelli Teixeira Nogueira \\ Universidade Federal de Alfenas (NIFAL/MG)
}

A presente pesquisa foi realizada com o objetivo de avaliar o nível de eficiência da utilização dos recursos renováveis nas universidades federais (UFs). O estudo é caracterizado como pesquisa descritivo-exploratória, com abordagem quantitativa do problema. Para atingir o objetivo proposto, mensurou-se o nível de eficiência relativa da utilização dos recursos renováveis, aplicando a metodologia Data Envelopment Analysis (DEA). Os resultados revelaram que, quanto ao uso do recurso renovável água, 8 Ufs, em média, apresentaram níveis de eficiência, por ano analisado. Na análise para o recurso renovável energia elétrica, em média, por ano analisado, 9 UFs apresentaram níveis de eficiência relativa. Já quanto à análise para o recurso papel, 11 UFs em média, por ano analisado, estavam na fronteira de eficiência. Portanto, os resultados apresentados e discutidos no presente trabalho permitiram ter uma visão geral do nível de eficiência da utilização dos recursos renováveis nas UFs. $O$ estudo pode contribuir para um melhor aproveitamento dos recursos naturais e para a melhoria da transparência na área pública.

Palavras-chave: recursos renováveis, nível de eficiência, universidades federais

[Artigo recebido em 19 de fevereiro de 2018. Aprovado em 14 de outubro de 2019.] 


\section{Eficiencia de la utilización de los recursos renovables en las universidades federales}

La presente investigación fue realizada con el objetivo de evaluar el nivel de eficiencia de la utilización de los recursos renovables en las universidades federales (UFs). El estudio es caracterizado como investigación descriptivo-exploratoria, hecha por medio de un abordaje cuantitativo del problema. Para alcanzar el objetivo propuesto, se midió el nivel de eficiencia relativa de la utilización de los recursos renovables, empleando la metodología Data Envelopment Analysis (DEA). Los resultados revelaron que, en cuanto al uso del recurso renovable agua, 8 UFs en media, presentaron niveles de eficiencia, por año evaluado. En el análisis para el recurso renovable energía eléctrica, en promedio, por año analizado, 9 UFs presentaron niveles de eficiencia relativa. Pero el análisis para el recurso papel, 11 UFs, en media, por año analizado, estaban en la frontera de eficiencia. Por lo tanto, los resultados presentados y discutidos en el presente trabajo permitieron tener una visión general del nivel de eficiencia de la utilización de los recursos renovables en las UFs. El estudio ha podido contribuir para un mejor aprovechamiento de los recursos naturales y para la mejoría de la transparencia en el área pública.

Palabras clave: recursos renovables, nivel de eficiencia, universidades federales

\section{Efficiency in the use of renewable resources at the federal universities}

The present research was conducted with the objective of evaluating the level of efficiency in the use of renewable resources at the federal universities (UFs). The study is characterized as a descriptive-exploratory research, with quantitative approach of the issue. In order to reach the proposed objective, measuring the level of relative efficiency of the use of renewable resources, applying the Data Envelopment Analysis (DEA). The results revealed that, regarding the use of the water renewable resource, in average, 8 FUs presented efficiency levels per analyzed year. In the analysis for the electric energy renewable resource, in average, per analyzed year, 9 FUs presented relative efficiency levels. For the analysis of the paper resource, $11 \mathrm{FUs}$, in average, per analyzed year, were on the borderline of efficiency. Therefore, the results presented and discussed in the present work allowed for a general view of the level of efficiency in the use of renewable resources at FUs. The study can contribute for a better exploitation of natural resources and for the improvement of transparency in the public sector.

Keywords: renewable resources, efficiency level, Federal Universities 


\section{Introdução}

No contexto nacional, desde a década de 1990, a gestão pública passa por grandes mudanças incentivadas por reivindicações sociais que pedem maior eficiência, transparência e eficácia na aplicação de recursos públicos. A qualidade do gasto público, cada vez mais, ganha destaque no âmbito acadêmico e governamental.

A eficiência impõe não só a necessidade do uso racional dos recursos financeiros públicos, mas também o uso racional dos recursos naturais. O Acordão no 1.752/11, do Tribunal de Contas da União, destaca que gerir bem os recursos financeiros e naturais é obrigação de todo e qualquer agente público.

Entre os valores que devem guiar a atividade estatal está a sustentabilidade. Assim, a sustentabilidade, com todas as suas consequências, deverá ser ponderada quando se aborda a eficiência.

De acordo com Walker e Brammer (2012), como o setor público tem maior preocupação com o bem-estar social, ele pode e deve ter um maior interesse nas questões de sustentabilidade do que o setor privado. A sustentabilidade no âmbito governamental tem sido cada vez mais um diferencial da nova gestão pública, em que os administradores passam a ser os principais agentes de mudança.

O acórdão TCU no 1752/2011 destaca a necessidade de um plano de ação visando orientar e incentivar todos os órgãos e entidades da administração pública federal a adotarem medidas para aumento da sustentabilidade e eficiência no uso dos recursos naturais, em especial os recursos papel, água e energia elétrica.

O Brasil possui o maior volume de água doce do mundo (MINISTÉRIO DO MEIO AMBIENTE, 2009). Mesmo assim, sofre com a escassez no meio da abundância e vive a maior crise de abastecimento da história. O país vive uma insegurança hídrica e os estados da Região Sudeste são os mais atingidos. A falta de água já compromete os grandes lagos das represas hidroelétricas.

O consumo de energia elétrica está cada vez maior, e é um fator bastante preocupante pela possibilidade de afetar a vida de toda a população. É essencial a sua utilização de modo inteligente, eficiente e eficaz. Nesse cenário, a eficiência energética assume grande importância no desempenho empresarial e no equilíbrio financeiro das famílias, sociedade e governo.

Os problemas ambientais relacionados à produção e consumo de papel são de grande escala, e um dos principais efeitos está relacionado ao alto consumo de matéria-prima, especialmente madeira, água e energia. O papel é um dos principais recursos naturais consumidos nas atividades desenvolvidas na administração pública. 
Esse cenário de escassez trouxe consigo a necessidade de que a proteção dos recursos naturais seja encarada como um dos objetivos estatais e que os riscos ambientais sejam evitados, minimizados ou canalizados por meio de políticas públicas também voltadas à adequada gestão eficiente dos recursos naturais, entre os quais se inclui a água, a energia e o papel.

Entre as entidades públicas, encontram-se as universidades federais (UFs). As universidades são instituições complexas que frequentemente adotam sistemas de deliberação colegiada, gestão descentralizada e tratam de um conjunto de tarefas extremamente diversificado.

O desafio da gestão das universidades consiste em equilibrar os sempre limitados recursos financeiros com a necessidade de gastos crescente. $O$ êxito da administração depende, entre outros fatores, da capacidade de implementar os projetos de melhorias dos gastos, considerando as variadas restrições administrativas e orçamentárias.

Nesse sentido, o objetivo deste estudo é avaliar o nível de eficiência da utilização dos recursos renováveis nas universidades federais.

A contribuição social do trabalho torna-se evidente, uma vez que as considerações dele resultantes podem subsidiar os gestores públicos no processo de tomada de decisão, possibilitando a concentração de esforços em investimentos ou ações que proporcionem, efetivamente, melhorias no desempenho das universidades federais quanto ao uso dos recursos renováveis.

Este estudo poderá contribuir para o aprofundamento teórico-empírico do tema, com o desenvolvimento da literatura sobre eficiência e uso dos recursos naturais no setor público, tendo em vista a indisponibilidade de pesquisas que evidenciam sua relação, bem como da aplicação da metodologia DEA.

Nesse contexto, percebe-se a importância de conhecer como os recursos renováveis estão sendo utilizados, uma vez que a conservação de tais recursos é tema na pauta de toda a sociedade, e os resultados necessitam ser evidenciados de forma mais ampla e clara.

Os resultados apresentados e discutidos no presente trabalho possibilitaram uma visão geral do nível de eficiência da utilização dos recursos renováveis nas universidades federais, e podem contribuir para a manutenção ou melhoria da gestão desses recursos. Possibilitaram, também, identificar as instituições que podem ser referências para as UFs com níveis de eficiência menores, por meio da verificação dos resultados das variáveis analisadas. 


\section{Referencial teórico}

\section{Sustentabilidade e o uso dos recursos renováveis na administração pública}

Atualmente há uma profusão de usos da palavra sustentável. Os antecedentes mais recentes da noção de sustentabilidade estão ligados ao primeiro informe do Clube de Roma, publicado em 1971, sobre a inviabilidade do crescimento econômico contínuo. No informe intitulado Os limites do crescimento, procurava-se gerar um contexto em que seria possível conciliar a economia com a conservação do meio ambiente (LIMA, 2006).

O uso do termo sustentabilidade no campo ambiental explodiu com o lançamento do Relatório Brundtland, intitulado Nosso futuro comum, publicado em 1987 pela Comissão Mundial sobre o Meio Ambiente e Desenvolvimento.

O Relatório Brundtland foi parte integrante de uma série de iniciativas anteriores à Agenda 21, e apontou a incompatibilidade entre o desenvolvimento sustentável e os padrões de produção e consumo vigentes. Nesse documento, o desenvolvimento sustentável é entendido como o desenvolvimento que satisfaz as necessidades presentes, sem colocar em risco a capacidade das gerações futuras de suprir suas próprias necessidades.

As características preponderantes do desenvolvimento sustentável objetivam: (a) na dimensão ambiental - ao uso responsável dos recursos naturais possibilitando a sua resiliência e autorreprodução; (b) na dimensão econômica-ao aumento eficiente da produção e do consumo, sem afetar a capacidade de renovação da natureza; e (c) na dimensão social -à distribuição dos bens necessários à sobrevivência humana, de modo que seja realizada equitativamente e não apenas por meio do pagamento. As dimensões da sustentabilidade se mesclam e favorecem uma nova forma de interação com a natureza (TEIXEIRA, 2013).

O homem sempre fez uso da natureza, primeiramente para o seu próprio sustento e mais tarde para produzir excedente. As sociedades capitalistas, que buscam incessantemente o lucro, extraem cada vez mais elementos da natureza, os chamados recursos naturais.

Para Andrade (2003), na busca de um conceito para recursos naturais, não é raro se deparar com conteúdos que passam pela definição de "bens disponibilizados pela natureza, aos quais o homem pode recorrer para satisfazer suas necessidades". Dessa forma, numa visão simplista, os recursos naturais têm sido entendidos como sendo, basicamente, a água, o solo, o minério, a vegetação, entre outros. 
$\mathrm{E}$, numa visão também reducionista, esses componentes têm recebido algumas classificações, sendo a principal respaldada na relação do componente em análise com ciclo natural ao qual o mesmo está vinculado. Daí a origem das duas principais categorias de recursos naturais: os renováveis e os não renováveis.

Os recursos naturais não renováveis abrangem todos os elementos que são usados nas atividades antrópicas, e que não têm capacidade de renovação, como o alumínio, o ferro, o petróleo, o ouro, o estanho, o níquel e muitos outros. Isso quer dizer que, quanto mais se extrai, mais as reservas diminuem. E diante desse fato é importante adotar medidas de consumo comedido, poupando recursos para o futuro.

Já os recursos naturais renováveis detêm a capacidade de renovação após serem utilizados pelo homem em suas atividades produtivas. Os recursos com tais características são florestas, água e solo. Caso haja o uso ponderado de tais recursos, certamente não se esgotarão (FREITAS, 2014).

A estratégia de mudança de cultura em favor do meio ambiente passa pela sensibilização e execução de práticas que visem ao uso racional dos recursos naturais, como, por exemplo, água, energia elétrica e papel.

A água é um recurso natural essencial, seja como componente de seres vivos, seja como meio de vida de várias espécies vegetais e animais, como elemento representativo de valores socioculturais e como fator de produção de bens de consumo e produtos agrícolas. Como fator de consumo das atividades humanas, a água também tem um papel importante. Como fator de produção de bens, a larga utilização na indústria e, notadamente, na agricultura, mostra a importância desse recurso natural (BASSOI; GUAZELLI, 2004) .

A abundância da água na natureza fez, no passado, com que fosse considerada como um bem livre, não econômico. No entanto, devido ao crescimento desordenado de cidades e regiões, com preocupantes níveis de demanda para os mais diversos usos da água, atualmente há um consenso no sentido de considerar a água como bem econômico (FIGUEIREDO JúNIOR, 2008).

Para Bliacheris (2012), há muitas medidas possíveis a serem adotadas pela administração pública com o objetivo de usar a água de modo mais racional. Passam pelo ajuste dos equipamentos hidráulicos ao acompanhamento constante do consumo, assim como o rápido conserto de vazamentos e campanhas de conscientização dos servidores. Boas práticas de gestão eficiente desse recurso podem ser implementadas, como a instalação de equipamentos como bacias sanitárias de baixo consumo, torneiras com aeradores e fechamento automático, entre muitas outras ações de fácil execução, mas com grande potencial de racionalização do consumo. 
Com relação à energia elétrica, a mesma pode ser gerada por meio de fontes renováveis de energia, como a força das águas e dos ventos, o sol e a biomassa, ou por fontes não renováveis, como combustíveis fósseis e nucleares. No Brasil, devido ao grande número de rios, a opção hidráulica é a mais usual, e apenas uma pequena parte da energia elétrica é gerada a partir de combustíveis fósseis, em usinas termelétricas.

Nogueira (2007) relata que, no Brasil, desde a crise do petróleo nos anos 1970, o Governo Federal tem promovido ações e programas visando reduzir as perdas energéticas. A crise serviu como um alerta para que muitos países pesquisassem novas fontes de energia.

Em 1981, com a criação do programa federal Conserve, por meio da Portaria MIC/ GM46, caracterizou-se o primeiro esforço de relevância para promover a eficiência energética na indústria. Em 1984, com a coordenação do Instituto Nacional de Metrologia, Normalização e Qualidade Industrial (Inmetro), foram iniciadas as ações do Programa de Etiquetagem (PBE), cujo objetivo estava voltado para a avaliação de desempenho de equipamentos energéticos e informações aos consumidores.

Com o agravamento da conjuntura do setor elétrico, foi criado em 1985, por meio da Portaria Interministerial no 1.877/1985, o Programa Nacional de Conservação de Energia Elétrica (Procel), constituído por vários subprogramas com ações nas áreas industrial, de saneamento, educação, edificações, prédios públicos, gestão energética municipal, informações, desenvolvimento tecnológico e difusão. 0 subprograma de Prédios Públicos (Procel-EPP) foi estruturado em 1997 e, ainda que algumas ações já estivessem em curso, foi a partir daí que o programa começou a estabelecer estratégias unificadas para atingir o objetivo de promover ações de eficiência energética para prédios públicos.

Nas atividades desenvolvidas pela administração pública, o papel é um dos principais recursos consumidos. O papel do tipo A4 $75 \mathrm{~g} / \mathrm{m}^{2}$ ocupa posição de destaque por fazer parte das atividades burocráticas. Não há órgão público sem uma impressora para produzir seus documentos. O impacto ambiental da impressão não se resume ao consumo de papel, mas também ao consumo de outros insumos como cartuchos e toner, o que impõe ao gestor público um desafio ainda maior, que envolve também a sua destinação de forma adequada (BLIACHERIS, 2012).

Os problemas ambientais relacionados à produção e consumo de papéis são de grande escala, estando os principais impactos relacionados ao alto consumo de matéria-prima, especialmente madeira, água e energia (MINISTÉRIO DO MEIO AMBIENTE, 2009). 
O acórdão do TCU $\mathrm{n}$ 1752/2011 destaca fatores importantes relacionados ao uso racional de papel, que incluem tanto o consumo como o descarte, com reflexos diretos tanto na redução do lixo urbano gerado como na inserção social e econômica de catadores de materiais recicláveis, gerando emprego e renda para esse segmento da população.

A redução no consumo de papel pela administração pública pode contribuir para a diminuição do corte de árvores, além de reduzir o consumo de água e energia elétrica utilizadas no processo de fabricação, que inclui processos de branqueamento do papel, com a utilização de cloro, que causa danos ao meio ambiente. Evitar a aquisição desse tipo de papel também se relaciona à busca do uso racional e sustentável do recurso (BRASIL, 2011).

O setor público, em função de seu perfil de grande consumidor, possui um potencial para estimular melhorias ambientais nos produtos e serviços disponibilizados no mercado, em inovações tecnológicas e em oportunidades para o desenvolvimento de um mercado de bens e serviços sustentáveis. É papel das autoridades públicas atuarem como líderes no processo de mudança nos padrões de consumo (PALMUjoki; PARIKKA-Alhola; EKroos, 2010).

No Brasil, a gestão pública socioambiental está representada pelo programa Agenda Ambiental na Administração Pública (A3P), criado em 2001, pelo Ministério do Meio Ambiente, para incorporar princípios de gestão ambiental no campo de ação da administração pública. Juntamente com a A3P podem-se ressaltar as ações relacionadas à implementação da ISO 26000, de responsabilidade social na administração pública brasileira, por meio de uma articulação de vários órgãos públicos no Brasil, o chamado Fórum Governamental de Responsabilidade Social (FERREIRA, 2012).

Para atingir seus objetivos, a A3P está estruturada em cinco eixos temáticos: (i) o uso racional dos recursos; (ii) as licitações sustentáveis; (iii) a gestão ambiental adequada de resíduos; (iv) a qualidade do ambiente de trabalho; e (v) a educação ambiental. A3P é uma ação voluntária que busca a adoção de novos padrões de produção e consumo sustentáveis dentro do Governo Federal. Além de buscar diminuir o impacto ambiental, também proporciona a redução dos custos e uma melhoria organizacional (FERREIRA, 2012).

O uso racional dos recursos naturais e bens públicos constitui um eixo temático da $\mathrm{A} 3 \mathrm{P}$, e enfatiza que usar racionalmente os recursos naturais e bens públicos implica usá-los de forma econômica e racional, evitando o desperdício. O eixo engloba o uso racional de energia, água e madeira, além do consumo de papel, copos plásticos, entre outros materiais de expediente (MINISTÉRIO do MEIO AMBIENTE, 2009). 
Para Ferreira (2012), o uso racional dos recursos compreende a economia de água, energia, combustíveis e outros bens consumidos pela administração pública nas suas atividades, de forma a evitar o desperdício e promover medidas capazes de gerar eficiência na utilização dos mesmos.

\section{Eficiência no setor público}

A partir da década de 1980, o Estado foi forçado a orientar a política econômica e, em especial, a conter suas despesas. Isso se deu principalmente em função da intensificação da crise fiscal e da maior exposição da economia nacionalà competição internacional. A palavra de ordem passou a ser cortar gastos. Não só o discurso de economistas acadêmicos, mas também de organismos internacionais, como Banco Mundial e o Fundo Monetário Internacional (FMI), passaram a enfatizar a qualidade do gasto público e não simplesmente o seu corte (ALONSO, 1999).

Di Giácomo (2005) relata que a Reforma do Estado tornou-se um tema central em muitos países, como resposta ao irreversível processo de globalização, e que representava uma dificuldade adicional na formulação e implementação das políticas públicas nacionais, caso estas desconsiderassem a nova realidade global. No caso brasileiro, esse fenômeno ocorreu em 1994, no Governo Fernando Henrique Cardoso, que tinha como uma de suas metas criar no país um serviço público moderno, profissional e eficiente, voltado para o atendimento das necessidades do cidadão.

Em 1995, foi implementado o Plano Diretor da Reforma do Aparelho de Estado, cujo objetivo era a readequação do aparelho estatal, por meio de programas com a perspectiva de mudança efetiva e consistente. Di Giácomo (2005) relata que não se tratava de promover alterações superficiais e sem maior significado, desvinculadas de uma ação mais ampla e coordenada. A questão de fundo era a superação do estilo burocrático-weberiano de gestão do Estado, caracterizado pelo aumento dos custos da máquina e pela falta de qualidade e ineficiência dos serviços públicos.

Como consequência do processo de adaptação a esse ambiente de reformas, surge a Lei Complementar no 101/2000, conhecida como Lei de Responsabilidade Fiscal (LRF), que criou condições para a implantação de uma nova cultura gerencial na gestão dos recursos públicos e incentivou o exercício da cidadania por meio da participação do cidadão no processo de acompanhamento da aplicação dos recursos e avaliação dos resultados. A LRF estabeleceu normas de finanças públicas voltadas para a responsabilidade na gestão fiscal, mediante ações de prevenção a riscos e correção de desvios que possam afetar o equilíbrio das contas públicas, com destaque para o planejamento, controle, transparência e responsabilização. 
O estabelecimento de padrões no planejamento e a mensuração dos resultados, conforme Mauss e Souza (2008), viabiliza, em um estágio seguinte, a avaliação de desempenho dos gestores e da entidade governamental, com o objetivo de demonstrar sua eficiência econômica, por meio do resultado econômico e o cumprimento da lei.

Há tempos, a sociedade brasileira clama por eficiência na administração pública. O princípio da eficiência foi introduzido expressamente no caput do art. 37 da Constituição Federal de 1988, por meio da Emenda Constitucional no 19/1998, que dispôs sobre os princípios e as normas de administração pública, com vistas a impor o controle das finanças e direcionar a busca da eficiência gerencial de uma gestão pública eficaz.

Anteriormente ao advento da Emenda Constitucional no 19/1998, o princípio da eficiência, de acordo com Santos (2003), achava-se implicitamente incluído entre os deveres do gestor público, significando que este deveria atuar com presteza, perfeição e rendimento funcional.

A eficiência na administração pública, conforme Castro (2010), é a otimização dos meios, é agir tendo como referência o melhor resultado, é gerir os recursos com alto rendimento, maximizando a relação custo/benefício.

Para Pindyck e Rubinfeld (1994), a eficiência refere-se à otimização de recursos e à ausência de desperdício. A eficiência é atingida com a utilização máxima dos recursos existentes, para satisfazer as necessidades e os desejos de indivíduos e organizações.

Já Caravantes e Bjur (1996) relatam que eficiência refere-se ao cumprimento de normas e à redução de custos, sendo usada para verificar se um programa público foi executado da maneira mais competente e com a melhor relação custo/resultado.

Dessa forma, pode se dizer que eficiência é a relação entre os produtos/serviços gerados (outputs) com os insumos utilizados (inputs), relacionando o que foi entregue e o que foi consumido de recursos, usualmente sob a forma de custos ou produtividade. A eficácia representa a quantidade e a qualidade de produtos e serviços entregues ao usuário (beneficiário direto dos produtos e serviços da organização).

A implantação de uma cultura de gerenciamento de gastos no setor público é um desafio a ser enfrentado pelo Estado e sociedade. A necessidade de uma forma mais transparente na gestão pública, que priorize a mensuração de gastos no governo, integra uma das fases essenciais para a transformação de paradigmas existentes sobre a importância do setor público como agente propulsor de geração de eficiência no uso de recursos públicos (MACHADO; HoLANDA, 2010).

$\mathrm{Na}$ literatura nacional e internacional, podem ser encontrados estudos anteriores, como dos autores Buzzigoli, Giusti e Viviani (2010), Chen e Chen (2011), Costa et al. 
(2012), Katharaki e Katharakis (2010), Kounetas et al. (2011), Nuintin (2014), Obadic e Aristovnik (2011), Rassouli-Currier (2012), Santos, Castaneda e Barbosa (2011), Sav (2012) e Wolszczak-Derlacz e Parteka (2011), que mensuraram a eficiência em universidades, porém, não foram considerados, especificamente, recursos naturais, e sim consideraram conjuntamente variáveis de volume e de desempenho como inputs e outputs.

\section{Procedimentos metodológicos}

Define-se esta pesquisa como sendo de natureza descritiva-exploratória, tendo em vista o problema construído e considerando os objetivos do estudo. Para Gil (1999), a aplicação de pesquisa descritiva combinada com pesquisa exploratória costuma ser utilizada por pesquisadores sociais que se preocupam com a atuação prática.

Quanto à abordagem do problema, o estudo possui enfoque quantitativo, devido ao fato de utilizar metodologias e técnicas estatísticas como a Data Envelopment Analysis (DEA) e as técnicas estatísticas descritivas. A abordagem quantitativa, segundo Richardson (1999), é caracterizada pela utilização da quantificação, tanto nas modalidades de coleta de informações, como no tratamento de dados.

Em 1978, com base no trabalho de Farrel (1957), Charnes, Cooper e Rhodes (1978) desenvolveram a metodologia Data Envelopment Analysis (DEA), caracterizando-se como uma técnica não paramétrica baseada na programação linear. Essa metodologia objetiva mensurar a eficiência de unidades tomadoras de decisão, também chamadas de Decision Marking Units (DMU), tais como empresas privadas, instituições públicas, financeiras, sem fins lucrativos, departamentos ou setores internos, entre outros.

A metodologia DEA mede a eficiência relativa de cada unidade com respeito aos melhores desempenhos observados. Esses melhores desempenhos determinam fronteiras de produção constituindo limites aos resultados alcançáveis com um dado conjunto de recursos.

Com relação ao objeto de estudo, o mesmo é composto pelas 63 universidades federais que o Brasil possui atualmente.

Os dados de natureza secundária são provenientes do Relatório de Gestão das Universidades Federais, disponíveis para livre consulta no portal do Tribunal de Contas da União (TCU) na internet, que contém a prestação de contas anual das universidades como determina o artigo 70 da Constituição Federal de 1988. O relatório é elaborado ainda, em conformidade com as disposições da Instrução Normativa do Tribunal de Contas da União - IN TCU no 63/2010 - e das orientações do órgão de controle interno. 
Após o levantamento dos dados nos Relatórios de Gestão das Universidades Federais, foram excluídas da análise DEA as instituições que não apresentaram os dados ou o fizeram de forma incompleta.

De posse dos dados, os mesmos foram organizados e descritos com a aplicação de técnicas da estatística descritiva. Para isso, foram utilizados softwares SPSS e o Microsoft Office Excell. Nessa etapa inicial das análises, buscou-se levantar informações sobre a média, desvio padrão, valores máximos e mínimos do conjunto de DMUs analisadas. E, para a aplicação da metodologia Data Envelopment Analysis (DEA), foi utilizado o software livre SIAD.

As variáveis necessárias para o cálculo da eficiência relativa das DMUs são divididas em inputs e outputs. A eficiência relativa de cada DMU é definida como a razão da soma ponderada de seus produtos (outputs) pela soma ponderada dos insumos necessários para gerá-los (inputs). Na DEA, essas variáveis são ponderadas por pesos calculados livremente ou de forma restrita por meio de programação linear, objetivando maximizar a eficiência de cada DMU em relação ao conjunto de referência.

Com a finalidade de atender ao objetivo desta pesquisa, as análises foram feitas com as variáveis descritas no Quadro 1.

\section{Quadro 1 - Variáveis selecionadas}

\begin{tabular}{|c|c|c|c|}
\hline Item & Variável selecionada & Descrição & Fonte dos dados \\
\hline \multicolumn{4}{|c|}{ Inputs } \\
\hline Input1 & Gastos com água & $\begin{array}{l}\text { Recurso financeiro } \\
\text { aplicado nas } \\
\text { universidades } \\
\text { federais com água }\end{array}$ & Relatório de Gestão \\
\hline Input 2 & $\begin{array}{l}\text { Gastos com energia } \\
\text { elétrica }\end{array}$ & $\begin{array}{l}\text { Recurso financeiro } \\
\text { aplicado nas } \\
\text { universidades } \\
\text { federais com energia } \\
\text { elétrica }\end{array}$ & Relatório de Gestão \\
\hline Input3 & Gastos com papel & $\begin{array}{l}\text { Recurso financeiro } \\
\text { aplicado nas } \\
\text { universidades } \\
\text { federais com papel }\end{array}$ & Relatório de Gestão \\
\hline \multicolumn{4}{|c|}{ Outputs } \\
\hline Output1 & Quantidade de água & $\begin{array}{l}\text { Total de metros } \\
\text { cúbicos }\end{array}$ & Relatório de Gestão \\
\hline Output 2 & $\begin{array}{l}\text { Quantidade de } \\
\text { energia elétrica }\end{array}$ & Total de $\mathrm{KW} / \mathrm{h}$ & Relatório de Gestão \\
\hline Output 3 & Quantidade de papel & $\begin{array}{l}\text { Quantidade de } \\
\text { resmas }\end{array}$ & Relatório de Gestão \\
\hline
\end{tabular}

Fonte: elaboração própria a partir dos dados da pesquisa. 
A decisão da escolha das variáveis utilizadas nesta pesquisa teve embasamento na DN/TCU no 119/2012, no acórdão TCU no 1752/2011 e no eixo temático uso racional dos recursos naturais e bens públicos, da Agenda Ambiental na Administração Pública (A3P), tendo como entrada o montante de recursos financeiros aplicados e como saída o total quantitativo consumido de água, energia elétrica e papel das universidades federais.

\section{Resultado da pesquisa}

As análises dos resultados foram realizadas e apresentadas individualmente na seguinte ordem: água, energia elétrica e papel.

\section{Estatística descritiva - recurso renovável - água}

A Tabela 1 apresenta a média, o desvio padrão, o valor máximo e o valor mínimo, com destaque para: (i) os valores gastos em moeda corrente ( $R \$$ ) e (ii) o consumo em metros cúbicos $\left(\mathrm{m}^{3}\right)$.

\section{Tabela 1 - Estatística descritiva - água}

Ano: 2011

\begin{tabular}{ccccc} 
Variável: Água & Média & Desvio padrão & Máximo & Mínimo \\
Valores $(\mathrm{R} \$$ ) & $1.515 .336,69$ & 2.401 .389 .15 & $11.884 .530,20$ & $2.773,74$ \\
& & & UFRJ & UFRR \\
Consumo $\left(\mathrm{m}^{3}\right)$ & 156.993 & 209.138 & 897.142 & 284 \\
\hline & & & UFMG & UFRR
\end{tabular}

Ano: 2012

\begin{tabular}{ccccc} 
Variável: Água & Média & Desvio padrão & Máximo & Mínimo \\
Valores (R\$) & $1.615 .284,66$ & $2.776 .826,91$ & $14.812 .918,55$ & $5.627,80$ \\
& & & UFRJ & UFRR \\
Consumo $\left(\mathrm{m}^{3}\right)$ & 156.207 & 218.887 & 936.841 & 586 \\
\hline & & & UFMG & UFRR
\end{tabular}

Ano: 2013

\begin{tabular}{|c|c|c|c|c|}
\hline Variável: Água & Média & Desvio padrão & Máximo & Mínimo \\
\hline \multirow[t]{2}{*}{ Valores (R\$) } & $1.774 .787,35$ & $3.018 .756,23$ & $16.843 .212,00$ & $4.924,28$ \\
\hline & & & UFRJ & UFRR \\
\hline \multirow[t]{2}{*}{ Consumo $\left(\mathrm{m}^{3}\right)$} & 157.349 & 209.127 & 1.055 .825 & 749 \\
\hline & & & UFRJ & UFRR \\
\hline \multicolumn{5}{|c|}{ Médias do período } \\
\hline Variável: Água & Média & Desvio padrão & Máximo & Mínimo \\
\hline Valores (R\$) & $1.635 .136,23$ & $2.732 .324,00$ & $14.513 .553,00$ & $4.441,94$ \\
\hline Consumo $\left(\mathrm{m}^{3}\right)$ & 156.850 & 212.384 & 963.269 & 540 \\
\hline
\end{tabular}

Fonte: elaboração própria a partir dos dados da pesquisa. 
Os resultados quantitativos apresentaram o seguinte: a média dos valores gastos com água pelas DMUs no período foi de $\mathrm{R} \$ 1.635 .136,23$. Os valores da média dos gastos em cada ano apresentaram um aumento de 6,60\% do ano de 2011 para 2012 e de 9,88\% de 2012 para 2013, perfazendo um total acumulado no período de $17,12 \%$ de aumento.

A média anual do consumo em metros cúbicos no período analisado foi de $156.850 \mathrm{~m}^{3}$. O consumo em metros cúbicos não acompanha tendencialmente os valores gastos, uma vez que a média anual apresenta uma redução de 0,50\% no ano de 2012 em relação ao de 2011, e um aumento de 0,73\% no ano de 2013 em comparação a 2012.

Pode-se perceber que o consumo médio em metros cúbicos de água, pelas DMUs, durante o período em análise, teve alterações em percentuais menores do que os observados nas análises dos valores pagos por tal recurso. Isso permite compreender que os aumentos médios dos gastos com água são provocados em função dos aumentos das tarifas cobradas pelas agências, e não por aumento de consumo em metros cúbicos pelas universidades federais.

Os valores máximos ( $\mathrm{R} \$$ ) pagos pela utilização do recurso água, durante todo o período de análise, foram efetuados pela UFRJ e tiveram um aumento acumulado de $41,72 \%$. O aumento dos gastos com água na UFRJ é devido, principalmente, ao aumento no consumo em metros cúbicos. No ano de 2013 a UFRJ apresentou, ainda, o valor máximo em consumo por $\mathrm{m}^{3}$.

$\mathrm{Na}$ análise dos máximos referente ao consumo em $\mathrm{m}^{3}$, a UFMG foi a DMU que apresentou o maior consumo em metros cúbicos nos anos de 2011 e 2012. Verificase que, apesar de consumir mais água, a UFMG desembolsou valores menores, se comparados, por exemplo, com a UFRJ, em razão do custo unitário pago, em média $52 \%$ menor.

Os valores mínimos identificados, tanto para os valores pagos quanto para as quantidades de metros cúbicos consumidos de água, foram obtidos pela UFRR.

A UFRR informou, no Relatório de Gestão, que os valores e quantidades de metros cúbicos consumidos de água correspondem aos valores auferidos pela companhia de água e esgoto de Roraima. Informou ainda que na UFRR existe uma captação própria que atende todo o Campus Paricarana e representa aproximadamente $80 \%$ de seu consumo.

\section{Resultados da mensuração do nível de eficiência relativa - água}

De acordo com a classificação geral apresentada na Tabela 2, no ano de 2011, das trinta e quatro universidades federais analisadas, cinco apresentaram o nível 
de eficiência igual a 1, quanto ao uso do recurso água, sendo elas: Ufersa, UFFS, UFRGS, UFSM e UFV.

Verifica-se que, das 29 UFs que estavam abaixo da fronteira, a UFABC, com um escore de eficiência de 0,134, obteve a última posição entre as universidades federais com eficiência menor que 1.

Tabela 2 - Água - resultado do nível de eficiência - 2011

\section{1}

\begin{tabular}{lccccc}
\hline UFs & Nível geral & Classificação & UFs & $\begin{array}{c}\text { Nível } \\
\text { geral }\end{array}$ & Classificação \\
\hline Ufersa & 1,000 & 1 & UFRJ & 0,432 & 18 \\
\hline UFFS & 1,000 & & Unifal & 0,417 & 19 \\
\hline UFRGS & 1,000 & & UFMA & 0,407 & 20 \\
\hline UFSM & 1,000 & & UFS & 0,364 & 21 \\
\hline UFV & 1,000 & & Ufla & 0,343 & 22 \\
\hline UFC & 0,889 & 6 & UnB & 0,338 & 23 \\
\hline UFU & 0,817 & 7 & Ufal & 0,302 & 24 \\
\hline UFCSPA & 0,790 & 8 & Unifei & 0,264 & 25 \\
\hline Unifap & 0,769 & 9 & Ufam & 0,244 & 26 \\
\hline UFPR & 0,755 & 10 & Unifesp & 0,242 & 27 \\
\hline UFMT & 0,670 & 11 & UFBA & 0,238 & 28 \\
\hline UFCG & 0,666 & 12 & Unirio & 0,234 & 29 \\
\hline Furg & 0,605 & 13 & Univasf & 0,230 & 30 \\
\hline Ufac & 0,557 & 14 & UFRB & 0,221 & 31 \\
\hline UFSC & 0,477 & 15 & Unir & 0,216 & 32 \\
\hline UFMS & 0,459 & 16 & UFG & 0,157 & 33 \\
\hline UFPE & 0,454 & 17 & UFABC & 0,134 & 34 \\
\hline
\end{tabular}

Fonte: elaboração própria a partir dos dados da pesquisa.

Para análise do resultado do nível de eficiência no ano de 2012, do recurso água, a Tabela 3 apresenta níveis de eficiência igual a 100\% em quatro UFs, sendo elas: Ufersa, UFMG, UFRGS e UFV. Na comparação entre os anos de 2011 e 2012, três UFs se mantiveram no nível de eficiência: Ufersa, UFRGS e UFV. 
As demais UFs tiveram níveis de eficiência abaixo de 1 , sendo que a UFABC manteve a última posição, com escore de eficiência de 0,114.

Tabela 3 Água - resultado do nível de eficiência - 2012

2012

\begin{tabular}{lccccc}
\hline UFs & Nível geral & Classificação & UFs & Nível geral & Classificação \\
\hline Ufersa & 1,000 & 1 & UFMT & 0,453 & 19 \\
\hline UFMG & 1,000 & & Unifal & 0,419 & 20 \\
\hline UFRGS & 1,000 & & UFRJ & 0,417 & 21 \\
\hline UFV & 1,000 & & Ufal & 0,377 & 22 \\
\hline Unilab & 0,981 & 5 & UFS & 0,376 & 23 \\
\hline UFMS & 0,937 & 6 & UFMA & 0,341 & 24 \\
\hline UFU & 0,834 & 7 & UnB & 0,315 & 25 \\
\hline UFSM & 0,795 & 8 & Ufla & 0,277 & 26 \\
\hline Unifap & 0,784 & 9 & UFBA & 0,256 & 27 \\
\hline UFC & 0,781 & 10 & Univasf & 0,229 & 28 \\
\hline UFCSPA & 0,755 & 11 & Unifei & 0,225 & 29 \\
\hline UFPE & 0,631 & 12 & UFRB & 0,220 & 30 \\
\hline UFFS & 0,608 & 13 & Unir & 0,216 & 31 \\
\hline Ufac & 0,590 & 14 & Unifesp & 0,215 & 32 \\
\hline UFPR & 0,587 & 15 & Unirio & 0,212 & 33 \\
\hline UFCG & 0,501 & 16 & Ufam & 0,149 & 34 \\
\hline FURG & 0,492 & 17 & UFG & 0,124 & 35 \\
\hline UFSC & 0,484 & 18 & UFABC & 0,114 & 36 \\
\hline
\end{tabular}

Fonte: elaboração própria a partir dos dados da pesquisa.

As instituições UFGD, UFPR, UFSM, UFU e UFV, conforme pode ser observado na Tabela 4, apresentaram, no ano de 2013, níveis de eficiência igual a 1 quanto ao uso do recurso água. Do total de trinta e cinco UFs analisadas, trinta ficaram posicionadas abaixo da fronteira, sendo a última posição ocupada pela Ufam. 
Tabela 4 Água - resultado do nível de eficiência - 2013

\section{3}

\begin{tabular}{lccccc}
\hline UFs & Nível geral & Classificação & UFs & $\begin{array}{c}\text { Nível } \\
\text { geral }\end{array}$ & Classificação \\
\hline UFGD & 1,000 & 1 & UFFS & 0,550 & 19 \\
\hline UFPR & 1,000 & & UFMS & 0,539 & 20 \\
\hline UFSM & 1,000 & & UFRB & 0,510 & 21 \\
\hline UFU & 1,000 & & Ufla & 0,507 & 22 \\
\hline UFV & 1,000 & & Ufac & 0,483 & 23 \\
\hline UFPE & 0,966 & 6 & UFMA & 0,435 & 24 \\
\hline Ufal & 0,950 & 7 & UFPB & 0,423 & 25 \\
\hline UFC & 0,834 & 8 & Unir & 0,383 & 26 \\
\hline Ufersa & 0,813 & 9 & Unifei & 0,357 & 27 \\
\hline UFMT & 0,793 & 10 & UFS & 0,354 & 28 \\
\hline UFCG & 0,730 & 11 & UnB & 0,345 & 29 \\
\hline Unilab & 0,712 & 12 & Unirio & 0,337 & 30 \\
\hline UFSC & 0,705 & 13 & UFBA & 0,272 & 31 \\
\hline Unifap & 0,656 & 14 & Unifesp & 0,241 & 32 \\
\hline UFCSPA & 0,629 & 15 & UFG & 0,224 & 33 \\
\hline Furg & 0,621 & 16 & UFABC & 0,183 & 34 \\
\hline Unifal & 0,582 & 17 & Ufam & 0,130 & 35 \\
\hline Univasf & 0,572 & 18 & & & \\
\hline Fon & & & & & 23 \\
\hline
\end{tabular}

Fonte: elaboração própria a partir dos dados da pesquisa.

De maneira geral, a análise do nível de eficiência relativa das universidades federais no período de 2011 a 2013, para o recurso renovável água, possibilitou identificar situações que serão indicadas a seguir.

A UFMG foi classificada na análise da DEA como supereficiente nos anos de 2011 e 2013. No ano de 2012 permaneceu com nível de eficiência igual a 1. Um aumento no consumo em $\mathrm{m}^{3}$ ocorrido no ano de 2012 de 4,43\% foi o que contribuiu para que a UF deixasse de ser supereficiente, mas se mantendo na fronteira. O que fez com que a mesma voltasse a ser supereficiente em 2013 foi uma economia no consumo de água de $28,15 \%$. 
A UFV apresentou, durante os três anos em análise, níveis de eficiência igual a 1. O custo unitário médio do $\mathrm{m}^{3}$ pago pela instituição foi de $\mathrm{R} \$ 2,70$, o que representa $36,40 \%$ do valor médio pago pelas demais UF's. Além disso, foi observado que o consumo de água foi reduzido em $56,53 \%$. Dessa forma, o baixo custo do $\mathrm{m}^{3}$ e a economia de água foram os fatores que contribuíram para a permanência da UFV na fronteira de eficiência.

Vale ressaltar que, em seu Relatório de Gestão, a UFV informou que, em sua unidade sede, possui serviço próprio de tratamento de água, o que contribui para o baixo valor gasto.

A UFRGS, nos anos de 2011 e 2012, obteve nível de eficiência igual a 1. No ano de 2013, foi classificada como supereficiente quanto ao uso do recurso água. 0 desempenho da UF deve-se ao fato de seu custo unitário médio do $\mathrm{m}^{3}$ ter sido $46,79 \%$ inferior ao valor da média. A análise apontou, ainda, um acréscimo no volume consumido de $6,46 \%$ durante o período; no entanto, esse valor não influenciou o nível de eficiência.

No ano de 2011, a UFSM foi localizada na fronteira de eficiência. Já no ano de 2012, a mesma ocupou a 8a posição na análise da DEA. O fato observado foi a ocorrência de um aumento de consumo de $14,13 \%$ no volume de água. Somado a isso, ocorreu ainda um aumento no custo do $\mathrm{m}^{3}$ de $12,53 \%$. No entanto, a UFSM voltou a ter nível de eficiência igual a 1 em 2013, por ter conseguido reduzir o consumo em $8,15 \%$.

Em 2013, a Ufersa não conseguiu manter-se na fronteira de eficiência, como ocorreu em 2011 e 2012. Sua posição na análise da DEA foi de 9o lugar, com escore de 0,813 ; isso pode estar relacionado com um aumento de consumo em $\mathrm{m}^{3}$ observado, no montante de $111,74 \%$.

A UFFS apresentou nível de eficiência em 2011. Nos anos de 2012 e 2013, sua posição na análise da DEA foi de 13 e 19o, com escores de 0,608 e 0,550 respectivamente. Foi verificado que ocorreu um aumento no custo da água de $29 \%$. Porém, o que representou maior peso nos gastos foi o nível de consumo, que durante o período analisado aumentou 104,75\%.

Uma redução no volume de água consumido de $3 \%$ e custo do $\mathrm{m}^{3} 21,06 \%$ abaixo da média das UFs foram fatores que possibilitaram a UFPR se posicionar na fronteira de eficiência no ano de 2013. Nos dois anos anteriores, sua posição na análise de eficiência foi 10 o em 2011, com escore de 0,755, e 15ㅇe em 2012, com escore de 0,587.

Para a UFU, o que contribuiu para obter nível de eficiência igual a 1 no ano de 2013 foi uma redução nos valores dos custos de 3,17\% do ano de 2012 para 2013. 
Um aumento no volume consumido de água de 19,71\% durante o período fez com que, nos anos de 2011 e 2012, a instituição ocupasse a 7ạ posição na análise da DEA, com escores de 0,834 e 0,817, respectivamente.

A UFABC ocupou a última posição na análise da DEA nos anos de 2011 e 2012, por ser a instituição que pagou o maior valor do custo unitário do $\mathrm{m}^{3}$ de água. Em 2013, a posição foi ocupada pela Ufam, por ter tido um aumento de $137,77 \%$ no volume de $\mathrm{m}^{3}$ consumidos de água.

A análise dos resultados quanto ao uso da água permitiu visualizar a tendência das unidades pesquisadas, em adotar, em maior ou menor grau, controles cujo objetivo é promover o uso da água de modo mais racional, o que vai ao encontro do que foi abordado no estudo de Bliacheris (2012).

Dessa forma, a mensuração do nível de eficiência relativa possibilitou identificar como está a eficiência do recurso renovável água das universidades federais.

\section{Estatística descritiva - recurso renovável - energia elétrica}

A Tabela 5 apresenta a média, o desvio padrão, o valor máximo e mínimo, com destaque para: (i) os valores gastos em moeda corrente (R\$); e (ii) o consumo em $\mathrm{KW} / \mathrm{h}$ do recurso energia elétrica.

Os resultados quantitativos apresentaram o seguinte: a média dos valores gastos com energia elétrica pelas DMUs, no período, foi de $\mathrm{R} \$ 5.190 .492,27$. Os valores da média dos gastos em cada ano apresentaram um aumento de 3,65\% do ano de 2011 para 2012; e, de 2012 para 2013, houve uma redução nos valores médios da ordem de $10,85 \%$.

A mesma tendência pode ser verificada na média de consumo em $\mathrm{KW} / \mathrm{h}$. Do ano de 2011 para 2012, ocorreu um aumento no consumo médio de 1,58\% e uma redução de $8,40 \%$ de 2012 para 2013. A média anual do consumo no período analisado foi de $13.906 .255 \mathrm{KW} / \mathrm{h}$. 


\section{Tabela 5 - Estatística descritiva- energia elétrica}

\begin{tabular}{|c|c|c|c|c|}
\hline \multicolumn{5}{|c|}{ Ano: 2011} \\
\hline Energia elétrica & Média & Desvio padrão & Máximo & Mínimo \\
\hline \multirow[t]{2}{*}{ Valores (R\$) } & $5.259 .642,10$ & $6.011 .993,10$ & $33.126 .115,33$ & $383.132,71$ \\
\hline & & & UFRJ & UFFS \\
\hline \multirow[t]{2}{*}{$\begin{array}{l}\text { Consumo } \\
(\mathrm{KW} / \mathrm{h})\end{array}$} & 14.159 .554 & 19.131.292 & 113.349 .127 & 829.931 \\
\hline & & & UFRJ & UFFS \\
\hline \multicolumn{5}{|c|}{ Ano: 2012} \\
\hline Energia elétrica & Média & Desvio padrão & Máximo & Mínimo \\
\hline \multirow[t]{2}{*}{ Valores (R\$) } & $5.451 .719,98$ & $6.473 .632,81$ & $36.338 .832,10$ & $501.248,46$ \\
\hline & & & UFRJ & UFFS \\
\hline \multirow[t]{2}{*}{$\begin{array}{l}\text { Consumo } \\
(\mathrm{KW} / \mathrm{h})\end{array}$} & 14.383 .819 & 20.675 .868 & 124.342 .225 & 1.007 .845 \\
\hline & & & UFRJ & UFFS \\
\hline
\end{tabular}

Ano: 2013

\begin{tabular}{lcccc}
\hline Energia elétrica & Média & Desvio padrão & Máximo & Mínimo \\
\hline Valores (R\$) & $4.860 .114,73$ & $4.546 .482,82$ & $23.236 .078,34$ & $162.916,95$ \\
\hline & & & UFRJ & Unila \\
\hline $\begin{array}{l}\text { Consumo } \\
(\mathrm{KW} / \mathrm{h})\end{array}$ & 13.175 .394 & 14.012 .621 & 79.507 .940 & 441.753 \\
\hline & & & UFRJ & Unila
\end{tabular}

Médias do período

\begin{tabular}{lcccc}
\hline Energia elétrica & Média & Desvio padrão & Máximo & Mínimo \\
\hline Valores (R\$) & $5.190 .492,27$ & $5.677 .369,00$ & $30.900 .341,00$ & $349.099,37$ \\
\hline $\begin{array}{l}\text { Consumo } \\
\text { (KW/h) }\end{array}$ & 13.906 .255 & 17.939 .927 & 105.733 .097 & 2.279 .529 \\
\hline
\end{tabular}

Fonte: elaboração própria a partir dos dados da pesquisa.

No período analisado, verifica-se que a redução nos valores pagos pela energia elétrica foi de 7,59\%, e, na redução do consumo em $\mathrm{KW} / \mathrm{h}$, foi de $6,95 \%$. Dessa forma, os gastos foram reduzidos por economia de consumo. 
Quanto aos valores máximos, seja pelos valores pagos ( $R \$$ ) ou pelo consumo $(\mathrm{KW} / \mathrm{h})$ de energia elétrica durante todo o período, os mesmos foram verificados na UFRJ e tiveram uma redução de $29,85 \%$ no período. O custo unitário pago pelo $\mathrm{KW} / \mathrm{h}$ foi de $\mathrm{R} \$$ 0,29 nos três anos, o que permite dizer que a redução do total pago pela UFRJ foi em função da redução do consumo. Os valores mínimos identificados, tanto para os valores pagos quanto para as quantidades de $\mathrm{KW} / \mathrm{h}$ consumidos de energia elétrica, foram apresentados pela UFFS nos anos de 2011 e 2012 e pela Unila em 2013.

\section{Resultados da mensuração do nível de eficiência relativa - DEA - energia elétrica}

De acordo com a classificação geral do resultado do nível de eficiência no ano de 2011 para o recurso energia elétrica, as universidades UFCSPA, UFMG, UFSCar e UFU alcançaram níveis de eficiência igual a 1 . O mesmo não ocorreu em 29 instituições que não obtiveram o mesmo desempenho, ficando o nível de eficiência abaixo de 1, conforme se observa na Tabela 6, que destaca a Unirio como a instituição que ocupou a última colocação na classificação geral.

Tabela 6 - Energia elétrica - resultado do nível de eficiência - 2011

\begin{tabular}{cccccc}
\hline & \multicolumn{5}{c}{2011} \\
UFs & Nível & Classificação & UFs & $\begin{array}{c}\text { Nível } \\
\text { geral }\end{array}$ & Classificação \\
\hline geral & 1 & UFPR & 0,840 & 18 \\
\hline UFCSPA & 1,000 & & UFCG & 0,833 & 19 \\
\hline UFSCar & 1,000 & & Furg & 0,833 & 20 \\
\hline UFU & 1,000 & & Ufersa & 0,824 & 21 \\
\hline UFRGS & 0,998 & 5 & UnB & 0,805 & 22 \\
\hline UFV & 0,975 & 6 & UFPE & 0,787 & 23 \\
\hline UFG & 0,973 & 7 & UFS & 0,783 & 24 \\
\hline Unifei & 0,972 & 8 & UFPEL & 0,751 & 25 \\
\hline Ufal & 0,965 & 9 & UFGD & 0,750 & 26 \\
\hline UFSC & 0,935 & 10 & UFSM & 0,737 & 27 \\
\hline Unifesp & 0,934 & 11 & UTFPR & 0,732 & 28 \\
\hline UFRR & 0,928 & 12 & UFBA & 0,732 & 29 \\
\hline
\end{tabular}




\begin{tabular}{cccccc}
\hline UFABC & 0,905 & 13 & UFRB & 0,664 & 30 \\
\hline Unifal & 0,900 & 14 & Unir & 0,625 & 31 \\
\hline Ufop & 0,886 & 15 & UFMS & 0,516 & 32 \\
\hline UFC & 0,843 & 16 & Unirio & 0,428 & 33 \\
\hline Ufla & 0,843 & 17 & & & \\
\hline
\end{tabular}

Fonte: elaboração própria a partir dos dados da pesquisa.

Pela análise do mesmo recurso no ano de 2012, pode-se verificar que a UFCSPA, a UFMG e a UFSCAR mantiveram o nível de eficiência, o que não ocorreu com a UFU. Já a UFV foi incluída entre as instituições com nível 1 de eficiência. A Tabela 7 mostra as demais universidades analisadas que apresentaram índices abaixo de 1, e mais uma vez aparece a Unirio, com escore de eficiência de 0,533 , na última posição da classificação geral.

Tabela 7 - Energia elétrica - resultado do nível de eficiência - 2012

2012

\begin{tabular}{cccccc}
\hline UFs & Nível geral & Classificação & UFs & Nível geral & Classificação \\
\hline UFCSPA & 1,000 & 1 & UnB & 0,866 & 18 \\
\hline UFMG & 1,000 & & UFPR & 0,852 & 19 \\
\hline UFSCar & 1,000 & & Ufla & 0,830 & 20 \\
\hline UFV & 1,000 & & UFG & 0,822 & 21 \\
\hline Ufal & 0,987 & 5 & UFPE & 0,806 & 22 \\
\hline UFRGS & 0,983 & 6 & UFGD & 0,790 & 23 \\
\hline Furg & 0,951 & 7 & UFCG & 0,790 & 24 \\
\hline Unifei & 0,949 & 8 & UTFPR & 0,762 & 25 \\
\hline UFABC & 0,948 & 9 & UFMS & 0,752 & 26 \\
\hline UFU & 0,944 & 10 & UFS & 0,743 & 27 \\
\hline Ufop & 0,939 & 11 & UFPEL & 0,727 & 28 \\
\hline Unifesp & 0,936 & 12 & UFRB & 0,724 & 29 \\
\hline UFC & 0,927 & 13 & UFSM & 0,705 & 30 \\
\hline UFRR & 0,900 & 14 & UFBA & 0,697 & 31 \\
\hline UFTM & 0,883 & 15 & Unir & 0,656 & 32 \\
\hline Unifal & 0,880 & 16 & Unirio & 0,533 & 33 \\
\hline Ufersa & 0,866 & 17 & & & \\
\hline Fon & 11 & & & & \\
\hline
\end{tabular}

Fonte: elaboração própria a partir dos dados da pesquisa. 
De um montante de trinta e seis UFs estudadas, quanto ao nível de eficiência relativa no uso de recurso energia elétrica, durante o ano de 2013, a Tabela 8 destaca as seis instituições que apresentaram níveis igual a 1, a saber: UFABC, UFCSPA, UFFS, UFPE, UFRGS e Unifesp. Observa-se que apenas a UFCSPA atingiu o nível de eficiência nos três anos consecutivos que constituem o período em análise. A UFMG não manteve, em 2013, os índices obtidos nos anos de 2011 e 2012, situação idêntica ocorrida com a UFSCar. Já a última posição na classificação geral, que nos anos anteriores foi ocupada pela Unirio, passou a ser da Ufac.

Tabela 8 - Energia elétrica - resultado do nível de eficiência - 2013

2013

\begin{tabular}{|c|c|c|c|c|c|}
\hline UFs & $\begin{array}{l}\text { Nível } \\
\text { geral }\end{array}$ & Classificação & UFs & $\begin{array}{l}\text { Nível } \\
\text { geral }\end{array}$ & Classificação \\
\hline UFABC & 1,000 & 1 & Ufersa & 0,806 & 19 \\
\hline UFCSPA & 1,000 & & UFS & 0,800 & 20 \\
\hline UFFS & 1,000 & & Furg & 0,795 & 21 \\
\hline UFPE & 1,000 & & UFPEL & 0,750 & 22 \\
\hline UFRGS & 1,000 & & UFMG & 0,736 & 23 \\
\hline Unifesp & 1,000 & & UFGD & 0,722 & 24 \\
\hline UFSCar & 0,987 & 7 & UFBA & 0,717 & 25 \\
\hline Ufla & 0,984 & 8 & Ufop & 0,699 & 26 \\
\hline UFSC & 0,976 & 9 & UTFPR & 0,691 & 27 \\
\hline UFC & 0,929 & 10 & UFTM & 0,649 & 28 \\
\hline UFRR & 0,912 & 11 & UFCG & 0,641 & 29 \\
\hline UFU & 0,897 & 12 & UFRB & 0,575 & 30 \\
\hline UFV & 0,875 & 13 & UFMS & 0,567 & 31 \\
\hline Ufal & 0,848 & 14 & Unir & 0,564 & 32 \\
\hline UFPR & 0,847 & 15 & UFG & 0,525 & 33 \\
\hline UFSM & 0,831 & 16 & Unirio & 0,479 & 34 \\
\hline Unifal & 0,821 & 17 & UFMT & 0,462 & 35 \\
\hline Unifei & 0,820 & 18 & Ufac & 0,457 & 36 \\
\hline
\end{tabular}

Fonte: elaboração própria a partir dos dados da pesquisa. 
De maneira geral, a análise do nível de eficiência relativa das universidades federais no período de 2011 a 2013, para o recurso renovável energia elétrica, possibilitou identificar situações que serão indicadas a seguir.

A UFCSPA foi a única instituição que permaneceu durante todo o período em análise com nível de eficiência igual a 1 . Foi verificado que o desempenho da instituição está relacionado ao fato de que a mesma teve uma redução nos custos dos $\mathrm{KW} / \mathrm{h}$ de 14,63\% do ano de 2012 para 2013, e, ainda, que, durante todo o período analisado, seus custos com o $\mathrm{KW} / \mathrm{h}$ estavam $5 \%$ menores do que a média dos custos das outras UFs.

Nos anos de 2011 e 2012, a UFMG e a UFSCar se posicionaram na fronteira de eficiência. A UFMG teve uma redução no consumo de $18,37 \%$; no entanto, essa redução não foi suficiente para que a instituição se mantivesse com nível de eficiência igual a $1 \mathrm{em}$ 2013. Tal fato pode ser atribuído ao aumento do custo do $\mathrm{KW} / \mathrm{h}$ de $12,19 \%$ ocorrido no mesmo período.

Já a UFSCar, diferente do ocorrido com a UFMG, apresentou uma redução no valor do custo do $\mathrm{KW} / \mathrm{h}$ de $9,37 \%$, mas houve um aumento no volume consumido de energia de $4,46 \%$, o que contribuiu para que a UFSCar não se posicionasse na fronteira eficiente no ano de 2013.

A UFU, no ano de 2011, apresentou nível de eficiência, mas não o manteve nos anos seguintes, atingindo eficiência abaixo de 1 , consequência de um aumento de $5 \%$ observado no volume de $\mathrm{KW} / \mathrm{h}$ consumidos e também de um aumento de 9,14\% dos custos no ano de 2012.

Apesar de manter constantes os custos do $\mathrm{KW} / \mathrm{h}$ durante o período em exame, a UFV foi localizada na fronteira eficiente somente no ano de 2012. No ano de 2013 , mesmo sendo verificada uma economia de $20,48 \%$ no volume de consumo, a análise da DEA apontou um índice de 0,875 para a UFV, que passou a ocupar a 13aㅡ posição em eficiência relativa às demais DMUs analisadas.

As instituições UFABC, UFPE, UFRGS e Unifesp apresentaram, nos anos de 2011 e 2012, níveis de eficiência abaixo de 1. Já no ano de 2013, essas instituições apresentaram as seguintes reduções dos custos: a UFABC, redução de 22,33\%; a UFPE, de 17,66\%; a UFRGS, de 7,69\%; e a Unifesp, de $56,06 \%$, o que possibilitou que fossem localizadas na fronteira de eficiência. Não foi observada nessas UFs redução nos níveis de consumo de $\mathrm{KW} / \mathrm{h}$.

Nas análises dos dados obtidos, observa-se a necessidade de programas que possam contribuir para a redução de consumo, como destaca Nogueira (2007), e também a adoção de ações voltadas para a avaliação de desempenho de equipamentos energéticos e informações aos usuários. 


\section{Estatística descritiva - recurso renovável - papel}

A Tabela 9 apresenta a média, o desvio padrão, o valor máximo e mínimo, com destaque para: (i) os valores gastos em moeda corrente (R\$); e (ii) o consumo em resmas do recurso papel.

\section{Tabela 9 - Estatística descritiva - papel}

Ano: 2011

\begin{tabular}{ccccc}
\hline Papel & Média & Desvio padrão & Máximo & Mínimo \\
\hline Valores (R\$) & $113.238,24$ & $91.866,25$ & $288.828,00$ & $2.958,00$ \\
\hline $\begin{array}{c}\text { Consumo } \\
\text { (resmas) }\end{array}$ & 12.719 & 10.352 & UFRN & Unilab \\
\hline & & & 33.338 & 300 \\
\hline
\end{tabular}

Ano: 2012

\begin{tabular}{ccccc}
\hline Papel & Média & Desvio padrão & Máximo & Mínimo \\
\hline Valores (R\$) & $116.618,12$ & $131.857,03$ & $747.900,00$ & $5.621,40$ \\
\hline $\begin{array}{c}\text { Consumo } \\
\text { (resmas) }\end{array}$ & 13.706 & 16.373 & UFRJ & Ufal \\
\hline & & & 97.000 & 660 \\
\hline
\end{tabular}

Ano: 2013

\begin{tabular}{ccccc}
\hline Papel & Média & Desvio padrão & Máximo & Mínimo \\
\hline Valores (R\$) & $150.279,53$ & $127.692,71$ & $435.228,00$ & $11.123,38$ \\
\hline $\begin{array}{c}\text { Consumo } \\
\text { (resmas) }\end{array}$ & 16.126 & 13.515 & UFRN & Unifei \\
\hline & & & 46.372 & 1.114 \\
\hline
\end{tabular}

Médias do período

\begin{tabular}{ccccc}
\hline Papel & Média & Desvio Padrão & Máximo & Mínimo \\
\hline Valores (R\$) & $126.711,96$ & $117.138,66$ & $490.652,00$ & $6.567,59$ \\
\hline $\begin{array}{c}\text { Consumo } \\
\text { (resmas) }\end{array}$ & 14.183 & 13.413 & 58.903 & 691 \\
\hline
\end{tabular}

Fonte: elaboração própria a partir dos dados da pesquisa. 
Os resultados quantitativos apresentaram o seguinte: a média dos valores gastos com papel pelas DMUs no período foi de $\mathrm{R} \$ 126.711,96$. Os valores da média dos gastos em cada ano apresentaram um aumento de 2,98\% do ano de 2011 para 2012 e de $28,86 \%$ do ano de 2012 para 2013 , o que totaliza um aumento acumulado no período de $32,71 \%$.

A média anual de resmas de papel consumidas no período analisado foi de 14.183. Os valores da média de consumo em cada ano apresentaram um aumento de 7,76\% do ano de 2011 para 2012 e de 17,65\% do ano de 2012 para 2013, totalizando um aumento no período de $26,78 \%$.

Pode-se perceber que o consumo médio de resmas de papel pelas DMUs teve alterações em percentual maior que o custo do papel no ano de 2012 , fato que não se repetiu no ano de 2013, quando os custos com papel apresentaram aumentos em percentuais superiores ao da quantidade de consumo de resmas. Dessa forma, os aumentos com os gastos com papel nas instituições são provocados tanto pelo aumento dos custos como pelo aumento de consumo.

O valor anual máximo ( $R \$$ ) pago pela utilização do recurso papel foi identificado na UFRN nos anos de 2011 e 2013, e na UFRJ em 2012. Foi identificado que o consumo em resmas pela UFRJ no ano de 2012 foi atípico, uma vez que a quantidade de 97.000 resmas está muito acima da média geral e também em discrepância com o consumo da própria instituição, que nos anos de 2011 e 2013 consumiu 15.960 e 39.622, respectivamente.

Em uma análise considerando a exclusão da UFRJ no ano de 2012, a UFRN passou a ser a DMU com valor máximo no ano de $\mathrm{R} \$ 380.257,36$.

Os valores mínimos identificados, tanto para os valores gastos como para o consumo de resmas, foram atribuídos às seguintes universidades federais: Unilab, no ano de 2011; Ufal, em 2012; e Unifei, no ano de 2013.

\section{Resultados da mensuração do nível de eficiência relativa - DEA - papel}

O uso do recurso papel durante o período em estudo é apresentado ano a ano, a seguir. A Tabela 10 mostra os resultados do nível de eficiência quantitativa de 2011. As instituições UFSCPA, Ufop, UFPR, UFSCar, UnB e Unifap são as que obtiveram níveis iguais a 1,0; outras 33 UFs ficaram abaixo do nível de eficiência; e, no último lugar na classificação geral, está posicionada a UFTM, com escore de eficiência de 0,524. 
Tabela 10 - Papel - resultado do nível de eficiência - 2011

\begin{tabular}{|c|c|c|c|c|c|}
\hline \multicolumn{6}{|c|}{2011} \\
\hline UFs & $\begin{array}{l}\text { Nível } \\
\text { geral }\end{array}$ & Classificação & UFs & $\begin{array}{l}\text { Nível } \\
\text { geral }\end{array}$ & Classificação \\
\hline UFCSPA & 1,000 & 1 & Ufam & 0,901 & 21 \\
\hline Ufop & 1,000 & & UFRB & 0,891 & 22 \\
\hline UFPR & 1,000 & & Unipampa & 0,888 & 23 \\
\hline UFSCar & 1,000 & & UFABC & 0,881 & 24 \\
\hline UnB & 1,000 & & UTFPR & 0,875 & 25 \\
\hline Unifap & 1,000 & & UFBA & 0,873 & 26 \\
\hline UFPB & 0,985 & 7 & UFGD & 0,872 & 27 \\
\hline UFFS & 0,973 & 8 & UFV & 0,870 & 28 \\
\hline UFU & 0,960 & 9 & Univasf & 0,868 & 29 \\
\hline UFRJ & 0,957 & 10 & UFPE & 0,834 & 30 \\
\hline UFPEL & 0,954 & 11 & UFS & 0,832 & 31 \\
\hline Ufersa & 0,950 & 12 & UFCG & 0,813 & 32 \\
\hline Unifesp & 0,950 & 13 & UFMG & 0,789 & 33 \\
\hline Furg & 0,945 & 14 & UFMA & 0,709 & 34 \\
\hline UFPI & 0,939 & 15 & UFRR & 0,680 & 35 \\
\hline Unir & 0,925 & 16 & Ufac & 0,677 & 36 \\
\hline UFSJ & 0,919 & 17 & UFRPE & 0,666 & 37 \\
\hline Unifei & 0,912 & 18 & UFMT & 0,626 & 38 \\
\hline UFG & 0,910 & 19 & UFTM & 0,524 & 39 \\
\hline Unifal & 0,903 & 20 & & & \\
\hline
\end{tabular}

Fonte: elaboração própria a partir dos dados da pesquisa.

Do ano de 2011 para o ano de 2012, apenas a Ufop conseguiu continuar no mesmo patamar de eficiência. As outras instituições que apresentaram níveis de eficiência igual a 1 em 2012 foram: UFRGS, UFRN, UFRR e Unilab. Já a Unifap apresentou o menor nível entre as outras 35 instituições pesquisadas que não atingiram a fronteira de eficiência, como pode ser observado na Tabela 11. 
Tabela 11 - Papel - resultado do nível de eficiência - 2012

\begin{tabular}{|c|c|c|c|c|c|}
\hline \multicolumn{6}{|c|}{2012} \\
\hline UFs & $\begin{array}{l}\text { Nível } \\
\text { geral }\end{array}$ & Classificação & UFs & $\begin{array}{l}\text { Nível } \\
\text { geral }\end{array}$ & Classificação \\
\hline Ufop & 1,000 & 1 & UFG & 0,903 & 21 \\
\hline UFRGS & 1,000 & & UFBA & 0,899 & 22 \\
\hline UFRN & 1,000 & & Unifal & 0,898 & 23 \\
\hline UFRR & 1,000 & & UTFPR & 0,893 & 24 \\
\hline Unilab & 1,000 & & UFRB & 0,884 & 25 \\
\hline UFPEL & 0,988 & 6 & UFGD & 0,880 & 26 \\
\hline Unifesp & 0,971 & 7 & UFPE & 0,878 & 27 \\
\hline Ufersa & 0,959 & 8 & Univasf & 0,878 & 28 \\
\hline UFPR & 0,954 & 9 & UFS & 0,867 & 29 \\
\hline Furg & 0,951 & 10 & Unir & 0,866 & 30 \\
\hline UFSCar & 0,950 & 11 & UFPI & 0,861 & 31 \\
\hline UFFS & 0,949 & 12 & Unifei & 0,854 & 32 \\
\hline UFV & 0,936 & 13 & UFCG & 0,846 & 33 \\
\hline UFCPA & 0,931 & 14 & Ufam & 0,826 & 34 \\
\hline UFU & 0,923 & 15 & UFMT & 0,823 & 35 \\
\hline Unipampa & 0,919 & 16 & UFMA & 0,798 & 36 \\
\hline UFSJ & 0,918 & 17 & UFMG & 0,787 & 37 \\
\hline UFTM & 0,910 & 18 & Ufac & 0,696 & 38 \\
\hline UFPB & 0,909 & 19 & UFRPE & 0,644 & 39 \\
\hline UFABC & 0,908 & 20 & Unifap & 0,607 & 40 \\
\hline
\end{tabular}

Fonte: elaboração própria a partir dos dados da pesquisa.

A exemplo do que ocorreu no ano anterior, em 2013, cinco instituições também foram consideradas eficientes quanto ao uso do recurso papel, sendo elas: UFCSPA, Ufersa, UFRGS, UFS e UFV. A Tabela 12 mostra o restante de instituições, sendo 32, de um montante de 37 UFs pesquisadas, em que o nível de eficiência ficou abaixo de 1. A UFABC obteve o menor resultado entre as universidades federais. 
Tabela 12 - Papel - resultado do nível de eficiência- 2013

\begin{tabular}{|c|c|c|c|c|c|}
\hline \multicolumn{6}{|c|}{2013} \\
\hline UFs & $\begin{array}{l}\text { Nível } \\
\text { geral }\end{array}$ & Classificação & UFs & $\begin{array}{l}\text { Nível } \\
\text { geral }\end{array}$ & Classificação \\
\hline UFCSPA & 1,000 & 1 & UFPEL & 0,895 & 20 \\
\hline Ufersa & 1,000 & & UFRB & 0,889 & 21 \\
\hline UFRGS & 1,000 & & UnB & 0,885 & 22 \\
\hline UFS & 1,000 & & Unifal & 0,883 & 23 \\
\hline UFV & 1,000 & & Unifap & 0,876 & 24 \\
\hline UFSJ & 0,994 & 6 & Ufam & 0,869 & 25 \\
\hline UFTM & 0,993 & 7 & UFG & 0,852 & 26 \\
\hline UFU & 0,974 & 8 & UFPB & 0,847 & 27 \\
\hline UFMS & 0,972 & 9 & UTFPR & 0,839 & 28 \\
\hline UFSCar & 0,968 & 10 & UFBA & 0,819 & 29 \\
\hline Unipampa & 0,960 & 11 & Unir & 0,807 & 30 \\
\hline UFRR & 0,940 & 12 & UFMA & 0,798 & 31 \\
\hline Unifesp & 0,939 & 13 & UFRN & 0,772 & 32 \\
\hline UFRPE & 0,938 & 14 & UFPI & 0,761 & 33 \\
\hline UFFS & 0,937 & 15 & UFPE & 0,758 & 34 \\
\hline UFMG & 0,915 & 16 & UFCG & 0,714 & 35 \\
\hline Univasf & 0,904 & 17 & Ufac & 0,714 & 36 \\
\hline UFMT & 0,900 & 18 & UFABC & 0,582 & 37 \\
\hline Furg & 0,899 & 19 & & & \\
\hline
\end{tabular}

Fonte: elaboração própria a partir dos dados da pesquisa.

De maneira geral, a análise do nível de eficiência relativa das universidades federais, no período de 2011 a 2013, para o recurso papel, possibilitou identificar situações que são indicadas a seguir.

A UFMS foi classificada com nível de supereficiência nos anos de 2011 e 2012, porém, não se manteve nessa posição no ano de 2013, devido ao aumento no consumo de papel de $20,49 \%$, acompanhado de um aumento no custo das resmas de $18,40 \%$. 
A análise de supereficiência classificou a UFRJ nos anos de 2012 e 2013 com nível de eficiência acima de 1 . No ano de 2012, um aumento no volume consumido de papel fez com que a instituição ficasse abaixo da fronteira eficiente.

A UFCSPA apresentou nível de eficiência igual a 1 nos anos de 2011 e 2013. Em 2012, devido a um aumento no consumo de resmas de 50,55\%, a instituição ficou com níveis de eficiência abaixo de 1.

No ano de 2011, as instituições UFPR, UFSCar e UnB estavam localizadas na fronteira de eficiência. No entanto, as mesmas não conseguiram manter os resultados nos anos seguintes, consequência de aumentos identificados no volume de resmas de papel consumido. A Unb apresentou o maior aumento, de $50,46 \%$, seguida pela UFPR, com percentual de $40,78 \%$ e a UFSCar, com um aumento de $27,03 \%$.

A UFRGS apresentou um desempenho positivo. Em 2011 foi classificada como supereficiente, e, nos anos seguintes, apresentou níveis de eficiência de 100\%. Uma redução nos níveis de consumo de 3,22\% em 2012 e 1,76\% em 2014 foram os fatores que contribuíram para sua permanência na fronteira eficiente.

Em 2012, as instituições UFRN e UFRR ocuparam lugar na fronteira eficiente. A UFRN, que no ano de 2011 foi classificada na análise de supereficiente, não conseguiu manter o mesmo desempenho em 2013, devido ao fato de ter tido um aumento nos custos das resmas de papel, de $33,37 \%$, em conjunto com um acréscimo no volume de consumo de $4,60 \%$.

A Unilab foi classificada como supereficiente em 2011 e 2013 e permaneceu na fronteira eficiente no ano de 2012. Foi verificada uma redução dos custos das resmas de papel de $12,98 \%$ durante o período analisado.

$\mathrm{Na}$ análise da DEA nos anos de 2011 e 2013, a UFRR foi localizada abaixo da fronteira de eficiência, ocupando as posições 35a e 12aㅡ, respectivamente. Uma redução dos custos das resmas de papel de $33,42 \%$ foi o que possibilitou à instituição obter nível de eficiência igual a 1, no ano de 2012.

Em 2013, a Ufersa, UFS e UFV foram as instituições que apresentaram níveis de eficiência igual a 1. Verificou-se uma redução dos custos das resmas durante o período analisado, de $12,88 \%$ na UFS, e de $3,88 \%$ na UFV. Já na Ufersa, a classificação na fronteira de eficiência se deve ao fato da manutenção dos custos das resmas de papel.

A Unifei foi apontada na classificação de supereficiência, no ano de 2013, devido a uma redução no consumo de papel de 43,10\% em relação a 2012.

Dessa forma, os resultados apontam concordância com o trabalho de Palmujoki, Parikka-Alora e Ekroos (2010), uma vez que, sendo as universidades federais, em 
função de seu perfil, grandes consumidoras de papel, as mesmas devem atuar como agentes inovadores no processo de mudança dos padrões de consumo.

\section{Considerações finais}

A sustentabilidade está diretamente relacionada ao desenvolvimento econômico. Como premissa básica da sustentabilidade está a utilização dos recursos naturais de forma racional, sem agressões ao meio ambiente. O setor público, sendo um grande consumidor de recursos renováveis, em suas atividades, deve buscar a conservação racional dos recursos renováveis e a proteção do ambiente. $O$ uso racional dos recursos compreende a economia de água, energia, papel e outros bens consumidos, de forma a evitar o desperdício e promover medidas capazes de gerar eficiência na utilização dos mesmos.

O objetivo do trabalho buscou avaliar o nível de eficiência da utilização dos recursos renováveis nas universidades federais. Para isso, utilizou-se a metodologia análise envoltória de dados, sendo as variáveis selecionadas os gastos financeiros e o consumo quantitativo com recursos renováveis, especialmente água, energia elétrica e papel.

Verificou-se que a maioria das UFs com níveis de eficiência iguais a 1 ou próximos de 1 evidenciaram, em seus relatórios de gestão, a prática de programas e ações voltados para a redução do nível de consumo e do custo dos recursos renováveis estudados, apresentados em $\mathrm{m}^{3}$ de água, $\mathrm{KW} / \mathrm{h}$ e resmas de papel.

Diante do exposto, acredita-se que os resultados apresentados e discutidos no presente trabalho possibilitaram uma visão geral do nível de eficiência da utilização dos recursos renováveis nas universidades federais e podem contribuir para a manutenção ou melhoria da gestão desses recursos. Possibilitaram também identificar as instituições que podem ser referências para as UFs com níveis de eficiência menores, por meio da verificação dos resultados das variáveis analisadas.

Acredita-se, ainda, que, por meio da mensuração da eficiência no uso dos recursos renováveis, este estudo pode contribuir para um melhor aproveitamento dos recursos naturais, para a melhoria da transparência na área pública, além de sua possível utilização na tomada de decisões relativas à aplicação de recursos naturais nas universidades federais.

Recomenda-se, em estudos futuros: (i) a análise da eficiência no processo de contratação dos recursos renováveis; (ii) a investigação da informação de custos para a gestão dos recursos renováveis no setor público; e (iii) a análise da eficiência a partir da implantação dos planos de logística sustentável, pelas universidades federais. 


\section{Referências bibliográficas}

Alonso, M. Custos no serviço público. Revista do Serviço Público, Brasília, v. 50, n. 1, p. 37-63, mar. 1999.

ANDRADE, L. A. Gestão e conservação de recursos naturais: uma abordagem técnica dos seus desafios e concepções. Agropecuária Técnica, Areia, v. 24, n. 2, p. 77-86, 2003.

BASSOI, L. J.; GUAZELLI, M. R. Controle ambiental da água. In: PHILIPPI JUNIOR, A.; RomÉRo, M. de A.; BRUNA, G. C. (Eds.). Curso de gestão ambiental. Barueri: Manole, 2004. 1045 p.

BLIACHERIS, M. W. Uso racional dos recursos na administração pública. In: BLIACHERIS, M. W.; FerReIRA, M. A. S. O (Orgs.). Sustentabilidade na administração pública: valores e práticas de gestão socioambiental. Belo Horizonte: Fórum, 2012. Cap. 2, p. 45-64.

BRASIL. Constituição (1988). Constituição da República Federativa do Brasil. São Paulo: Saraiva, 1988. 349 p.

BRASIL. Acordão TCU no 1.752 de 05 de julho de 2011. Tribunal de Contas da União, Brasília, DF, 06 jul. 2011.

BRASIL. Decisão Normativa TCU no 119 de 18 de janeiro de 2012. Altera redação e inclui unidades no Anexo I, altera texto dos itens 10.1 e 10.2 da Parte A do Anexo II, altera texto do item 40 e inclui os itens 41, 42, 43, 44 e 45 na Parte B do Anexo II, altera itens da Parte C do Anexo II, todos da Decisão Normativa TCU n.o 119, de 18 de janeiro de 2012. Tribunal de Contas da União, Brasília, DF, 13 jun. 2012.

BRASIL. Instrução Normativa TCU no 63 de 01 de setembro de 2010. Estabelece normas de organização e de apresentação dos relatórios de gestão e das peças complementares que constituirão os processos de contas da administração pública federal, para julgamento do Tribunal de Contas da União, nos termos do art. 70 da Lei no 8.443, de 1992. Tribunal de Contas da União, Brasília, DF,02 set. 2010.

BRASIL. Lei Complementar no101, de 04 de maio de 2000. Lei de Responsabilidade Fiscal (LRF). Estabelece normas de finanças públicas voltadas para a responsabilidade na gestão fiscal e dá outras providências. Diário Oficial da União, Brasília, DF, 05 maio 2000.

BUZZIGOLI, L.; GIUSTI, A.; VIVIANI, A. The evaluation of university departments: a case study for firenze. International Advances in Economic Research, Oxford, v. 16, n. 1, p. 24-38, fev. 2010.

CARAVANTES, G. R.; BJUR, W. Readministração em ação: a prática da mudança rumo ao sucesso. Makron Books, 1996. 240 p.

CASTRO, D. P. Auditoria, contabilidade e controle interno no setor publico: integração das áreas do ciclo de gestão: contabilidade, orçamento e auditoria e organização dos controles internos como suporte à governança corporativa. 3. ed. São Paulo: Atlas, 2010. $603 \mathrm{p}$.

Charnes, A.; CoOPER, W. W.; RHOdes, E. Measuring the efficiency of decision making units. Europen Journal of Operation, Amsterdam, v. 2, n. 6, p. 429-444, nov. 1978. 
CHEN, J.; CHEN, S. Inno-qual efficiency of higher education: empirical testing using data envelopment analysis. Expert Systems with Applications, New York, v. 38, n. 3, p. 1823-1834, mar. 2011.

COSTA, E. M. et al. Eficiência e desempenho no ensino superior: uma análise da fronteira de produção educacional das Ifes brasileiras. Revista Economia Contemporânea, Rio de Janeiro, v. 16, n. 3 p. 415-440, set./dez. 2012.

DI GıACOMO, W. Á. O new public management no Canadá e a gestão pública contemporânea. Interfaces Brasil/Canadá, Rio Grande, v. 5, n. 5, p. 155-170, 2005.

FARRELL, M. J. The measurement of productive efficiency. Journal of Royal Statistical, London, v. 120, n. 3 p. 253-281, 1957.

FERREIRA, M. A. S. O. Apontamentos sobre a gestão socioambiental na administração pública brasileira. In: BIACHERIS, M. W.; FERREIRA, M. A. S. O. (Org.). Sustentabilidade na Administração Pública: valores e práticas de gestão socioambiental. Belo Horizonte: Forum, 2012. p. 21-44.

FIGUEIREDO JÚNIOR, J. V. de. Custo da água com vistas à sustentabilidade dos sistemas urbanos de abastecimento. 2008. 170 p. Tese (Doutorado em Recursos Naturais) Universidade Federal de Campina Grande, Campina Grande, 2008.

FREITAS, E. Os recursos naturais. Brasil Escola, Uberlândia, 2014. Disponível em: <http://www.brasilescola.com/geografia/os-recursos-naturais.htm>. Acesso em: 09 out. 2014.

GIL, A. C. Métodos e técnicas de pesquisa social. São Paulo: Atlas, 1999. 220 p.

KATHARAKI, M.; KATHARAKIS, G. A comparative assessment of Greek universities' efficiency using quantitative analysis. International Journal of Educational Research, Amsterdam, v. 49, n. 4-5, p. 115-128, 2010.

KOUNETAS, K. et al. Departmental efficiency differences within a Greek university: an application of a DEA and Tobit analysis. International Transactions in Operational Research, Oxford, v. 18, n. 5, p. 545-559, set. 2011.

LIMA, S. F. Introdução ao conceito de sustentabilidade, aplicabilidade e limites. Cadernos da Escola de Negócios da Unibrasil, Curitiba, v. 4, n. 4, p. 01-14, jan./dez. 2006.

MACHADO, N.; HolANDA, V. B. Diretrizes e modelo conceitual de custos para o setor público a partir da experiência no governo federal do Brasil. Revista de Administração Pública, Rio de Janeiro, v. 44, n. 4, p. 791-820, jul./ago. 2010.

MAuss, C. V.; SouZA, M. A. de. Gestão de custos aplicada ao setor público: modelo para mensuração e análise da eficiência e eficácia governamental. São Paulo: Atlas, 2008. $210 \mathrm{p}$.

Ministério do MeIo AMBIENTE. Agenda ambiental na administração pública - A3P. 5. ed. Brasília: MMA, 2009. 99 p.

NogueirA, L. A. H. Uso racional: a fonte energética oculta. Estudos Avançados, São Paulo, v. 21, n. 59, p. 91-105, jan./abr. 2007. 
NUINTIN, A. A. Eficiência da aplicação de recursos públicos nas universidades federais. 2014. 169 p. Tese (Doutorado em Administração) - Universidade Federal de Lavras, Lavras, 2014.

OBADIĆ, A.; ARISTOVNIK, A. Relative efficiency of higher education in Croatia and Slovenia: an international comparison. Amfiteatru Economic, Romania, v. 13, n. 30, p. 362-376, 2011.

PALMUJOKI, A.; PARIKKA-AlholA, K.; EKROOS, R. I. Green public procurement: analysis on the use environmental critéria in contracts. Review of European Community \& International Environmental Law, Oxford, v. 19, n. 2, p. 250-262, out. 2010.

PINDYCK, R. S.; RUBINFELD, D. L. Microeconomia: teoria microeconômica. São Paulo: Makron Books, 1994. 968 p.

RASSOULI-CURRIER, S. The relationship between institutional efficiency and instructional quality in higher education. Creative Education, Amsterdam, v. 3, n. 2, p. 224-227, abr. 2012.

RICHARDSON, R. J. Pesquisa social: métodos e técnicas. São Paulo: Atlas, 1999. 336 p. SANtos, A. C. Princípio da eficiência da administração pública. São Paulo: LTr, 2003. $389 \mathrm{p}$.

SAntos, C. S.; CAStAnedA, M. V. N. G.; BARbosa, J. D. Indicadores de desempenho das IFES da região nordeste: uma análise comparativa. In: CoLóQUIO INTERNACIONAL SOBRE GESTÃo UNIVERSITÁRIA NA AMÉRICA Do SUL, 11., 2011, Florianópolis. Anais... Florianópolis: Inpeau, 2011.

SAV, G. T. Managing operating efficiencies of publicly owned universities: American university stochastic frontier estimates using panel data. Advances in Management \& Applied Economics, New York, v. 2, n. 1, p. 1-23, 2012

TEIXEIRA, G. K. M. D. Mudanças de paradigmas e as possibilidades da sustentabilidade ambiental na sociedade de consumo: algumas reflexões teóricas. Delos: desarrollo local sostenible, Málaga, v. 16. n. 18, out. 2013. Disponível em: <http://www.eumed. net/rev/delos/ 18/sustentabilidade-ambiental.html>. Acesso em: 14 mar. 2014.

WALKER, H.; BRAMMER, S. The relationship between sustainable procurement and e-procurement in the public sector. International Journal of Production Economics, Amsterdam, v. 140, n. 1, p. 256-268, nov. 2012.

Wolszczak-Derlacz, J.; PARTEKA, A. Efficiency of European public higher education institutions: a two-stage multicountry approach. Scientometrics, Amsterdam, v. 89, n. 3, p. 887-917, dez. 2011.

\section{Maria Aparecida Curi}

Universidade Federal de Alfenas (UNIFAL/MG). Doutora em Administração pela Universidade Federal de Lavras. Bachael em Administração e Ciências Contábeis pela Faculdade Cenecista de Varginha. Mestre em Administração - Gestão Estratégica de Negócios pela Faculdade Cenecista de Varginha. Pós-graduada em Contabilidade e Gerência Financeira pela Universidade São Judas Tadeu. Professora da Universidade Federal de Alfenas -MG. mariaaparecidacuri@gmail.com, http://lattes.cnpq.br/9842265897660893 


\section{Gideon Carvalho de Benedicto}

Universidade Federal de Lavras (UFLA). Doutor em Controladoria e Contabilidade pela Universidade de São Paulo. Mestre em Ciências Contábeis e Atuariais pela Pontifícia Universidade Católica de São Paulo. Bacharel em Ciências Contábeis pela Faculdade de Ciências e Letras de Campo Mourão. Professor associado da Universidade Federal de Lavras. gideon.benedicto@gmail.com, http://lattes.cnpq.br/1080019231954948

\section{Francisval de Melo Carvalho}

Universidade Federal de Lavras (UFLA). Doutor em Administração de Empresas pela Universidade Presbiteriana Mackenzie. Bacharel em Engenharia Agronômica pela Escola Superior de Agricultura de Lavras (ESAL). Professor Associado da Universidade Federal de Lavras. francarv@dae.ufla.br, http://lattes.cnpq.br/6639373563533147

\section{Adriano Antonio Nuintin}

Universidade Federal de Alfenas (UNIFAL/MG). Doutor em Administração pela Universidade Federal de Lavras. Mestre em Controladoria e Contabilidade pela Universidade de São Paulo. Bacharel em Administração e Ciências Contábeis. Professor na Universidade Federal de Alfenas - Campus Varginha. nuintin@yahoo.com.br, http://lattes. cnpq.br/1098108871789832

\section{Leandro Rivelli Teixeira Nogueira}

Universidade Federal de Alfenas (NIFAL/MG). Mestre e Doutor em Administração pela Universidade Federal de Lavras. Bacharel em Administração pela Universidade Federal de Viçosa. Especialista em Controladoria e Finanças Empresariais. Professor Adjunto na Universidade Federal de Alfenas - Campus Avançado de Varginha. Professor no Instituto de Ciências Sociais Aplicadas. leandrorivelliteixeiranogueira@gmail.com, http://lattes.cnpq. br/0984564353850567 